\title{
KARAKTERISTIK PANCING TEGAK YANG DIOPERASIKAN DI PERAIRAN BANGKA BELITUNG
}

\author{
Sawon*) \\ "Teknisi Litkayasa pada Balai Riset Perikanan Laut, Jakarta \\ Teregristasi I tgl. 6/3/2006; Disetujui terbit tgl. 19/7/2006
}

\section{PENDAHULUAN}

Kabupaten Belitung yang merupakan bagian dari Propinsi Bangka Belitung secara geografis, terletak pada posisi $107^{\circ} 35^{\prime}-108^{\circ} 18^{\prime} \mathrm{BT}$ dan $2^{\circ} 30^{\prime}-3^{\circ} 15^{\prime}$ LS. Luas wilayah daratan $4.800 \mathrm{~km}^{2}$, luas laut $29.606 \mathrm{~km}^{2}$, luas wilayah pesisir $1.900 \mathrm{~km}^{2}$, dan panjang garis pantai $195 \mathrm{~km}$. Jumlah pulau kecil 189 buah yang terbagi dalam wilayah Kabupaten Belitung dan Kabupateng Belitung Timur.

Perairan Bangka Belitung, merupakan salah satu wilayah penyebaran jenis-jenis ikan pelagis dan demersal, seperti ikan layang (Decapterus spp.), ikan kembung (Rastrelliger spp.), ikan kakap merah (Lutjanus spp.), dan ikan kurisi (Nemipterus spp.). Ikan-ikan tersebut merupakan hasil tangkapan utama di wilayah lepas pantai (off-shore), khususnya di perairan Pejantan (dekat Pontianak) dan perairan Natuna.

Salah satu alat tangkap yang dioperasikan di perairan Bangka Belitung adalah pancing tegak. Di samping itu juga ada alat tangkap lain seperti pukat ikan dan purse seine. Pancing tegak adalah alat tangkap ramah lingkungan yang dioperasikan secara manual, pada kedalaman air antara 40 sampai dengan $150 \mathrm{~m}$. Setiap gulung terdiri atas 7 buah mata pancing no. 18 yang dipasang secara tegak pada monofilamen diameter $2 \mathrm{~mm}$, panjang 40 sampai dengan $200 \mathrm{~m}$. Disusun secara berurutan dari bawah ke atas, dengan jarak antara pancing 4,0 $\mathrm{m}$, dan pada bagian paling bawah dipasang pemberat dari timah $(\mathrm{Pb})$ dengan berat $0,5 \mathrm{~kg}$, supaya kedudukan tali pancing tetap tegak.

Tujuan penulisan makalah adalah menyajikan data dan informasi mengenai dimensi teknis kapal, karakteristik alat tangkap, aspek operasional, dan biologi ikan. Penelitian dilakukan terhadap pancing tegak yang sedang beroperasi di atas kapal motor milik nelayan setempat.

\section{DAERAH PENANGKAPAN}

Daerah penangkapan ikan pelagis kecil dan ikan demersal pantai (neritic) tersebar dari jarak 1 sampai dengan 3 mil dari Pantai Bangka-Belitung. Lokasi perikanan bagan di Bangka terdapat di sepanjang Pantai Utara Bangka (seperti di Sungai Liat, Koba, dan Pangkal Pinang) dan di sebelah barat Belitung (Tanjung Binga) sekitar $17 \mathrm{~km}$ di sebelah utara Kota Tanjung Pandan. Bagan dioperasikan dengan menggunakan alat bantu lampu petromak yang berjumlah 5 sampai dengan 6 buah per unit. Basis perikanan payang terdapat di Sungai Liat dan Pangkal Pinang (Bangka), sedang di Belitung terdapat di pulaupulau kecil di sekitar pantai utara, dari Pulau Selat Nasik di sebelah barat (dekat Tanjung Pandan) sampai dengan ke Dusun Malang Lepau dan Pulau Bukulimau di sebelah timur Pulau Belitung (dekat Manggar). Daerah penangkapan payang terdapat di perairan utara Bangka (kira-kira 5 sampai dengan 10 mil dari pantai), Pulau Tujuh di sebelah barat laut dan Pulau Kelasa di sebelah timur, pada kedalaman perairan sekitar $25 \mathrm{~m}$. Peta lokasi daerah penangkapan dan produksi ikan pelagis kecil dan demersal, seperti tertera dalam Lampiran 2 dan Gambar 1.

\section{DESKRIPSI KAPAL DAN ALAT TANGKAP}

\section{Kapal}

Kapal yang dioperasikan dengan alat tangkap pancing tegak adalah kapal kayu yang dibuat oleh galangan kapal di Badau tahun 2003. Ukuran panjang kapal (LOA) 15,0 m, lebar (W) 2,9 m, dalam (D) 1,6 $\mathrm{m}$, dan bobot kotor $5 \mathrm{GT}$, dengan kecepatan 5,5 knot. Mesin dompeng merk Kubota $24 \mathrm{PK}$, pancing ditarik secara manual, melaut harian. Kapal ini diawaki oleh 5 orang $A B K$, yang terdiri atas 1 orang pemilik kapal dan 4 orang pemancing. 


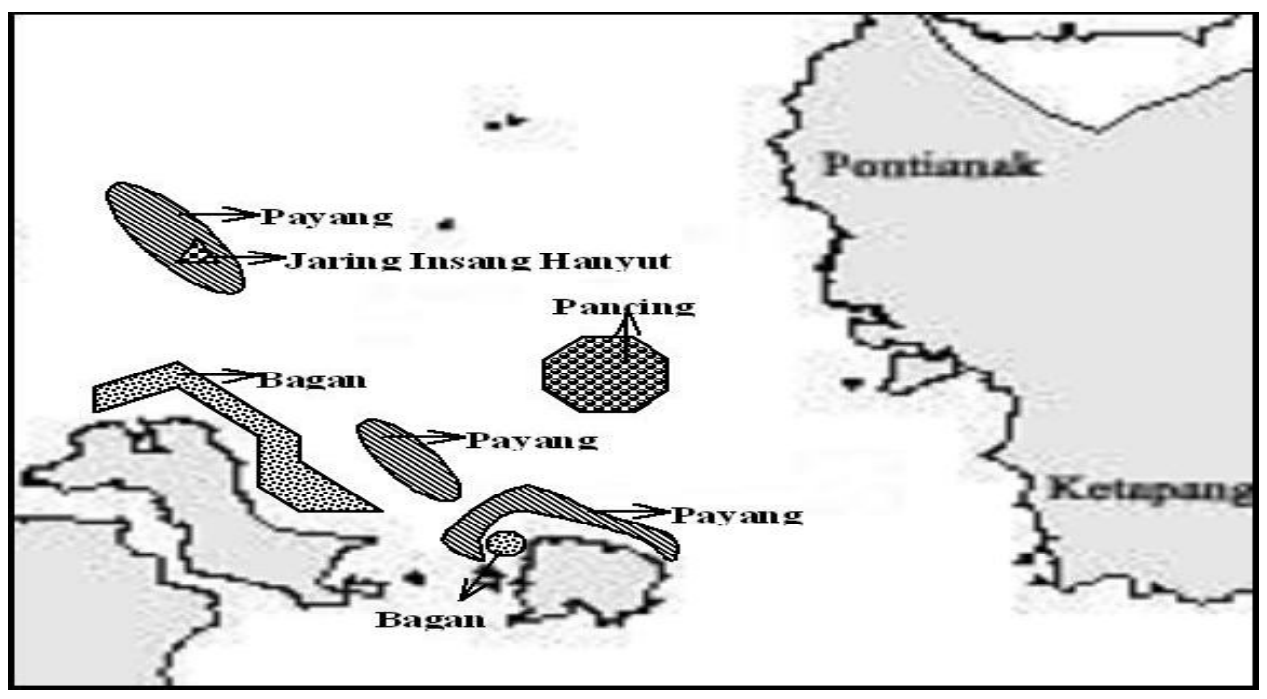

Gambar 1. Daerah penangkapan ikan pelagis kecil menurut jenis alat tangkapnya di perairan utara Bangka Belitung.

\section{Desain Alat Tangkap}

Dimensi tiap unit pancing tegak di Belitung secara umum terbagi dalam 9 bagian utama yaitu: penggulung bulat dari sintetis diameter $15 \mathrm{~cm} \times$ panjang $30 \mathrm{~cm}$, tali utama monofilament diameter 1 $\mathrm{mm}$, panjang $100 \mathrm{~m}$, tali cabang monofilament diameter $0,5 \mathrm{~mm}$, panjang $50 \mathrm{~cm}$, mata pancing stainlis ukuran no.18, swivel stainlis panjang $4 \mathrm{~cm}$, pemberat timah $(\mathrm{Pb})$ bobot $0,5 \mathrm{~kg}$, pelampung bulat dari sintetis diameter $10 \mathrm{~cm}$, jarak antar pancing 4 $\mathrm{m}$, dan jarak dari pancing terakhir ke pemberat $2 \mathrm{~m}$.

Setiap kapal terdiri atas 4 penggulung yang masing-masing terdiri atas 7 buah mata pancing yang berarti jumlah 1 unit $=28$ mata pancing, tertera dalam Gambar 2.

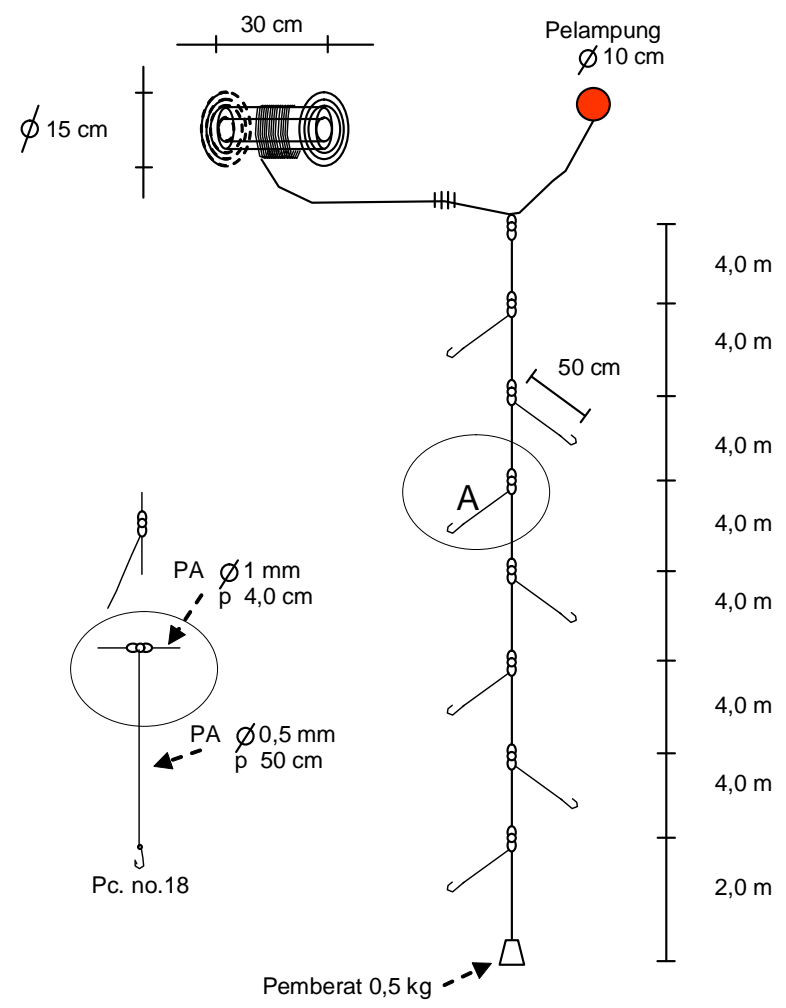

Bagian utama :

1. Penggulung dari sintetis diameter $15 \mathrm{~cm} \times$ panjang $30 \mathrm{~cm}$

2. Tali utama dari PA diameter $1 \mathrm{~mm} \times$ panjang $100 \mathrm{~m}$

3. Tali cabang dari PA diameter $0,5 \mathrm{~mm} \times$ panjang $50 \mathrm{~cm}$

4. Mata pancing dari stainlis no. 18

5. Swivel stainlis panjang $4 \mathrm{~cm}$

6. Pemberat dari timah $(\mathrm{Pb}) \mathrm{a}^{\prime} .0,5 \mathrm{~kg}$

7. Pelampung bulat dari sintetis diameter $10 \mathrm{~cm}$

8. Jarak antar pancing $4 \mathrm{~m}$

9. Jarak dari pancing ke pemberat $2 \mathrm{~m}$.

Gambar 2. Rancang bangun pancing tegak. 


\section{Cara Pengoperasian Alat}

1. Pengoperasian pancing tegak dilakukan memakai kapal motor dari kayu berukuran panjang $15,0 \mathrm{~m}$, lebar 2,9 m, dalam 1,6 m, dan bobot kotor $5 \mathrm{GT}$.

2. Pengoperasian dilakukan secara bersamaan oleh 4 orang pemancing pada kanan kiri lambung kapal. Setiap orang hanya menggunakan 1 penggulung dengan jumlah 7 buah mata pancing.

3. Penangkapan dilakukan mulai pukul 05.30-12.00 waktu setempat. Lama menunggu setiap penurunan pancing berkisar antara 5 sampai dengan 10 menit, kemudian pancing dinaikkan untuk diambil ikan hasil tangkapannya, dan setelah selesai pancing diturunkan berulang kali sampai dengan pukul 12.00 waktu setempat.

4. Umpan yang digunakan adalah kembung (Restrelliger brachysoma), layang (Decapterus russelii), dan lemuru (Sardinella longiceps).

5. Penarikan pancing dilakukan secara manual dengan tenaga manusia.

6. Pengemasan ikan hasil tangkapan dilakukan dengan cara memasukkan dalam peti berisolasi dan diberi es balok.

\section{Komposisi Hasil Tangkapan}

Hasil tangkapan pancing tegak Kabupaten Belitung pada bulan Juli tahun 2005 terdiri atas 41 jenis dengan bobot $761,0 \mathrm{~kg}$, dan didominasi oleh ikan daun bambu (Chorinemus tol) $32,0 \mathrm{~kg}$ atau $4,21 \%$, ikan kuwe (Caranx sp.) $32,0 \mathrm{~kg}$ atau $4,21 \%$, ikan ekor kuning (Caesio erythrogaster) $30,5 \mathrm{~kg}$ atau $4,01 \%$, tongkol banyar (Euthynnus affinis) $30,0 \mathrm{~kg}$ atau $3,94 \%$, bentong (Selar crumenopthalmus) $24,5 \mathrm{~kg}$ atau $3,22 \%$, dan kembung perempuan (Restrelliger brachysoma) $23,5 \mathrm{~kg}$ atau 3,09\%, tertera dalam (Lampiran 3).

Pengukuran terhadap ikan hasil tangkapan meliputi: panjang cagak (FL), panjang total (TL), dan bobot ikan (W). Dari hasil pengukuran di TPI Tanjung Pandan dan TPI Baro berhasil diukur ikan sebanyak 744 ekor, terdiri atas 16 spesies adalah seperti tertera dalam (Lampiran 5).

\section{Laju Tangkap}

Hasil tangkapan pancing tegak pada bulan Juli 2005 dari 12 kapal sebanyak 1.393 ekor dengan jumlah mata pancing 532 buah. Dengan demikian, laju tangkap rata-rata 38,19\%. Laju tangkap tertinggi pada kapal ke-3 sebanyak 183 ekor dengan jumlah mata pancing 70 buah atau dengan laju tangkap $38,28 \%$. Laju tangkap terendah pada kapal ke-7 sebanyak 76 ekor dengan jumlah mata pancing 35 buah atau dengan laju tangkap $46,05 \%$, tertera dalam (Lampiran 4).

\section{KESIMPULAN}

1. Perairan Bangka Belitung, merupakan salah satu wilayah penyebaran jenis-jenis ikan pelagis dan demersal, seperti ikan layang (Decapterus spp.), ikan kembung (Rastrelliger spp.), ikan kakap merah (Lutjanus spp.), dan ikan kurisi (Nemipterus spp.). Ikan-ikan tersebut merupakan hasil tangkapan utama ikan pelagis dan demersal di lepas pantai (off-shore), khususnya di perairan Pejantan (dekat Pontianak) dan perairan Natuna.

2. Daerah penangkapan ikan pelagis kecil dan ikan demersal pantai (neritic) tersebar dari jarak 1 sampai dengan 3 mil dari pantai Bangka Belitung.

3. Armada kapal ikan berjumlah 2.502 unit bobot antara 5-25 GT, dengan jumlah alat tangkap 27.236 unit.

4. Produksi ikan di Kabupaten Belitung tahun 20042005 mengalami kenaikan sebesar $21,49 \%$, dari $58.370,683$ ton menjadi $70.915,345$ ton.

5. Komposisi hasil tangkapan pancing tegak di TPI Tanjung Pandan dan Baro terdiri atas 41 jenis ikan, dominan hasil tangkapan adalah daun bambu (Chorinemus tol) sebesar 4,21\%.

6. Laju tangkap hook rate pancing tegak di TPI Tanjung Pandan dan Baro adalah $38,19 \%$.

7. Kisaran panjang berat (FL) dan (W) ikan hasil tangkapan pancing tegak di TPI Tanjung Pandan dan Baro antara 15,0-90,5 cm dan 40-7.500 g.

\section{UCAPAN TERIMA KASIH}

Penulis mengucapkan terima kasih sebesarbesarnya kepada Bapak Drs. Kunto Purnomo, MS dan Drs. Bambang Sumiono yang telah memberikan saran dan koreksinya, juga kepada pengetik naskah, dan penerbit sehingga dapat terlaksananya tulisan ini. 
Lampiran 1. Spesifikasi jumlah nelayan, sarana dan prasana, armada kapal, dan alat tangkap

\begin{tabular}{|c|c|c|c|c|c|c|c|}
\hline \multirow{2}{*}{ No. } & \multirow{2}{*}{ SPESIFIKASI } & \multicolumn{5}{|c|}{ KECAMATAN } & \multirow{2}{*}{ JUMLAH } \\
\hline & & TJ. PANDAN & BADAU & MEMBALONG & SEL. NASIK & SIJUK & \\
\hline 1. & Nelayan & 1,428 & 695 & 2,331 & 2,254 & 2,531 & 9,239 \\
\hline \multirow[t]{14}{*}{2.} & Sarana dan prasarana & & & & & & \\
\hline & - Pelabuhan Nusantara & 1 & - & - & - & - & 1 \\
\hline & - Pelabuhan Perikanan & 1 & - & - & - & - & 1 \\
\hline & - Pangkalan Pendaratan Ikan (PPI) & - & - & - & 1 & - & 1 \\
\hline & - Tempat Pelelangan Ikan (TPI) & 1 & - & - & 1 & - & 2 \\
\hline & - Dermaga/Tambat labuh & 4 & 2 & 2 & 4 & - & 12 \\
\hline & - Dok/Slip way & 1 & - & - & - & - & 1 \\
\hline & - Perbengkelan & 3 & 1 & - & 1 & 3 & 8 \\
\hline & - Balai pertemuan nelayan & 1 & - & - & 1 & - & 2 \\
\hline & - Galangan kapal & 1 & 1 & - & 1 & 3 & 6 \\
\hline & - Pabrik es & 6 & - & - & - & 1 & 7 \\
\hline & - Cold storage & 7 & - & - & - & - & 7 \\
\hline & - Depot es & 1 & - & - & 1 & - & 2 \\
\hline & Jumlah Sarana dan Prasarana & 27 & 4 & 2 & 10 & 7 & 50 \\
\hline \multirow[t]{9}{*}{3.} & Armada Kapal & & & & & & \\
\hline & - Jukung & 10 & 122 & 153 & 64 & 160 & 509 \\
\hline & $-\mathrm{MT}<5 \mathrm{GT}$ & 7 & - & 7 & - & 44 & 58 \\
\hline & - MT 5 - 10 GT & - & - & - & - & - & - \\
\hline & $-\mathrm{MT}>10 \mathrm{GT}$ & - & - & - & - & - & - \\
\hline & $-\mathrm{KM}<5 \mathrm{GT}$ & 304 & 129 & 510 & 412 & 555 & 1,910 \\
\hline & - KM 5 - 10 GT & 14 & - & - & 5 & 6 & 25 \\
\hline & $-\mathrm{KM}>10 \mathrm{GT}$ & - & - & - & - & - & - \\
\hline & Jumlah Armada Kapal & 335 & 251 & 670 & 481 & 765 & 2,502 \\
\hline \multirow[t]{18}{*}{4.} & Alat Tangkap & & & & & & - \\
\hline & - Payang & 8 & 262 & 8 & 9 & 212 & 499 \\
\hline & - Jaring insang & 16 & 64 & 116 & 4 & 485 & 685 \\
\hline & - Pukat tarik/PI & 14 & 2 & 4 & 36 & 633 & 689 \\
\hline & - Trammel net & - & 4 & - & 4 & 3,871 & 3,879 \\
\hline & - Jaring cumi & 6 & 2 & - & 4 & - & 12 \\
\hline & - Jaring muroami & 2 & - & - & 4 & - & 6 \\
\hline & - Jaring kepiting & 57 & 16 & 1,099 & 158 & 8,533 & 9,863 \\
\hline & - Purse seine & 6 & - & - & - & - & 6 \\
\hline & - Anco & 2 & - & 16 & 4 & - & 22 \\
\hline & - Bagan & 14 & 23 & 140 & - & 169 & 346 \\
\hline & - Sungkur & 13 & - & - & 11 & - & 24 \\
\hline & - Bubu & 932 & - & 1,803 & 405 & 485 & 3,625 \\
\hline & - Pancing tegak/Ranggung & 762 & 13 & 1,462 & 21 & 1,217 & 3,475 \\
\hline & - Pancing tonda & 385 & 350 & 343 & 306 & 303 & 1,687 \\
\hline & - Pancing rawai & 444 & - & 260 & 8 & 485 & 1,197 \\
\hline & - Lainnya & 64 & 40 & - & 384 & 733 & 1,221 \\
\hline & Jumlah Alat Tangkap & 2,725 & 776 & 5,251 & 1,358 & 17,126 & 27,236 \\
\hline
\end{tabular}


Lampiran 2. Produksi ikan di Kabupaten Belitung, Propinsi Bangka Belitung Tahun 2004 dan 2005

\begin{tabular}{llrrrr}
\hline & & \multicolumn{4}{c}{ PRODUKSI IKAN } \\
\cline { 3 - 6 } No. & KECAMATAN & \multicolumn{2}{c}{$\mathbf{2 0 0 4}$} & $\mathbf{2 0 0 5}$ \\
\cline { 3 - 6 } & & \multicolumn{1}{c}{ (Rp.) } & ( TON ) & (Rp.) \\
\hline 1. & Tanjung Pandan & $5,970.114$ & $5,970,114,000$ & $6,839.770$ & $6,839,771,600$ \\
2. & Membalong & $7,885.075$ & $7,885,075,000$ & $8,706.400$ & $8,706,395,500$ \\
3. & Sijuk & $6,538.304$ & $6,538,304,000$ & $7,898.970$ & $7,898,972,400$ \\
4. & Badau & $3,157.805$ & $3,157,805,000$ & $5,072.230$ & $5,072,225,500$ \\
5. & Selat Nasik & $11,511.460$ & $11,511,461,000$ & $12,013.770$ & $12,013,772,300$ \\
6. & Manggar & $7,315.545$ & $7,315,545,000$ & $8,725.400$ & $8,706,394,500$ \\
7. & Dendang & $3,306.156$ & $3,306,156,000$ & $5,975.115$ & $5,975,114,100$ \\
8. & Gantung & $8,493.940$ & $8,493,940,000$ & $10,511.460$ & $10,511,461,000$ \\
9. & Kampit & $4,192.284$ & $4,192,284,000$ & $5,172.230$ & $5,072,225,500$ \\
& JUMLAH & $\mathbf{5 8 , 3 7 0 . 6 8 3}$ & $\mathbf{5 8 , 3 7 0 , 6 8 4 , 0 0 0}$ & $\mathbf{7 0 , 9 1 5 . 3 4 5}$ & $\mathbf{7 0 , 7 9 6 , 3 3 2 , 4 0 0}$ \\
\hline
\end{tabular}

Catatan:

Pada tahun 2004 telah terjadi pemekaran wilayah di Kabupaten Belitung terbagi menjadi 2 Kabupaten, yaitu Kabupaten Belitung dan Kabupaten Belitung Timur 
Lampiran 3. Komposisi hasil tangkapan pancing tegak di TPI Tanjung Pandan dan Baro, Dati II Belitung, Bangka Belitung bulan Juli 2005

\begin{tabular}{|c|c|c|c|c|}
\hline \multirow{2}{*}{ No. } & \multirow{2}{*}{ NAMA LOKAL } & \multirow{2}{*}{ NAMA LATIN } & \multicolumn{2}{|c|}{ PANCING TEGAK } \\
\hline & & & $(\mathbf{k g})$ & $(\%)$ \\
\hline 1. & Tenggiri batang & (Scomberomorus lineatus) & 12.5 & 1.64 \\
\hline 2. & Tenggiri papan & (Scomberomorus guttatus) & 10.5 & 1.38 \\
\hline 3. & Nyunglas & (Acanthacybium solandri) & 16.0 & 2.10 \\
\hline 4. & Kembung (P) & (Restrelliger brachysoma) & 23.5 & 3.09 \\
\hline 5. & Kembung (L) & (Rastrelliger kanagurta) & 17.5 & 2.31 \\
\hline 6. & Bentong/Condong & (Selar crumenopthalmus) & 24.5 & 3.22 \\
\hline 7. & Tetengkek/Garonggong & (Megalaspis cordyla) & 23.0 & 3.02 \\
\hline 8. & Pisang-pisang/Tongkol & (Auxis thazard) & 12.5 & 1.64 \\
\hline 9. & Tongkol banjar/Komo & (Euthynnus affinis) & 30.0 & 3.94 \\
\hline 10. & Daun bambu/Kelempes & (Chorinemus tol) & 32.0 & 4.21 \\
\hline 11. & Talang-talang & (Chorinemus tala) & 23.5 & 3.09 \\
\hline 12. & Lencam/Tambak/Bangbangan & (Lutjanus monostigmus) & 12.5 & 1.64 \\
\hline 13. & Kurisi & (Nemipterus nematopharus) & 14.5 & 1.91 \\
\hline 14. & Tanda-tanda/Bambangan & (Lutjanus rivulatus) & 12.5 & 1.64 \\
\hline 15. & Kurisi bali/Jambret & (Pristipomoides filamentosus) & 15.0 & 1.97 \\
\hline 16. & Kurisi bali & (Etelis carbunculus) & 23.0 & 3.02 \\
\hline 17. & Kurisi bali & (Pristipomoides typus) & 20.5 & 2.69 \\
\hline 18. & Kakap merah/ganas & (Lutjanus crythropterus) & 14.5 & 1.90 \\
\hline 19. & Kakap sawo & (Lutjanus sebae) & 9.5 & 1.25 \\
\hline 20. & Jenaha/gando & (Lutjanus johni) & 12.5 & 1.64 \\
\hline 21. & Kakap merah/Bambangan & (Lutjanus lemniscatus) & 17.0 & 2.23 \\
\hline 22. & Bambangan & (Pinjalo pinjalo) & 12.5 & 1.64 \\
\hline 23. & Kakap merah & (Lutjanus altifrontalis) & 16.0 & 2.10 \\
\hline 24. & Kerapu lumpur & (Epinephelus sp.) & 15.0 & 1.97 \\
\hline 25. & Kerapu sunu & (Plectropoma leopardus) & 16.0 & 2.10 \\
\hline 26. & Gerot-gerot/Semingok & (Pomadasys macullatus) & 12.5 & 1.64 \\
\hline 27. & Bulat/Kuwe & (Pomadasys sp.) & 24.5 & 3.22 \\
\hline 28. & Ekor kuning & (Caesio erythrogaster) & 30.5 & 4.01 \\
\hline 29. & Kuwe/Manggali & (Caranx sp.) & 32.0 & 4.21 \\
\hline 30. & Kuwe/Tumpak & (Caranx sexfasciatus) & 21.5 & 2.83 \\
\hline 31. & Kiper/Kitang & (Carangidae) & 17.5 & 2.30 \\
\hline 32 & Selar kuning & (Selaroides leptolepis) & 23.5 & 3.09 \\
\hline 33 & Kara ketok & (Caranx sp.) & 11.5 & 1.51 \\
\hline 34 & Sunglir & (Elagatis bipinnulatus) & 20.5 & 2.69 \\
\hline 35 & Golok-golok & (Chirosentrus dorab) & 18.0 & 2.37 \\
\hline 36 & Mayung & (Arius thalassinus) & 15.0 & 1.97 \\
\hline 36 & Utik & (Arius sp.) & 16.5 & 2.17 \\
\hline 38 & Cendro/Tudak & (Tylosurus crocodilus) & 25.5 & 3.35 \\
\hline 39 & Pari kembang & (Trygon kuhlii) & 23.5 & 3.09 \\
\hline 40 & Pari burung & (Aetomylus nichofii) & 16.5 & 2.17 \\
\hline 41 & Cucut/Hiu & (Carcharias dussmieri) & 15.5 & 2.04 \\
\hline \multicolumn{3}{|c|}{ Jumlah } & 761.0 & $100 \%$ \\
\hline
\end{tabular}


Lampiran 4. Laju tangkap hook rate pancing tegak di TPI Tanjung Pandan dan Baro, Dati II Belitung, Bangka Belitung bulan Juli 2005

\begin{tabular}{|c|c|c|c|c|c|}
\hline \multirow{2}{*}{ No. Kapal } & \multicolumn{2}{|c|}{ Pancing Tegak } & \multirow{2}{*}{$\begin{array}{l}\text { Jumlah } \\
\text { Pancing }\end{array}$} & \multirow{2}{*}{$\begin{array}{l}\text { Hasil } \\
\text { (ekor) }\end{array}$} & \multirow{2}{*}{$\begin{array}{c}\text { Hook Rate } \\
(\%)\end{array}$} \\
\hline & Rool & Satuan & & & \\
\hline 1 & 4 & 7 & 28 & 86 & 32,56 \\
\hline 2 & 7 & 10 & 70 & 145 & 48,28 \\
\hline 3 & 7 & 10 & 70 & 183 & 38,25 \\
\hline 4 & 5 & 7 & 35 & 99 & 35,36 \\
\hline 5 & 4 & 7 & 28 & 94 & 29,80 \\
\hline 6 & 4 & 7 & 28 & 106 & 26,42 \\
\hline 7 & 5 & 7 & 35 & 76 & 46,05 \\
\hline 8 & 5 & 7 & 35 & 88 & 39,80 \\
\hline 9 & 7 & 10 & 70 & 155 & 45,16 \\
\hline 10 & 7 & 10 & 70 & 176 & 39,80 \\
\hline 11 & 5 & 7 & 35 & 98 & 35,71 \\
\hline 12 & 4 & 7 & 28 & 87 & 32,18 \\
\hline Hook Rate & 64 & - & 532 & 1,393 & 38,19 \\
\hline
\end{tabular}


Lampiran 5. Kisaran panjang berat ikan hasil tangkapan pancing tegak di TPI Tanjung Pandan dan Baro, Belitung, bulan Juli 2005

\begin{tabular}{|c|c|c|c|c|c|}
\hline \multirow{3}{*}{ No. } & \multirow{3}{*}{ Jenis Ikan } & \multicolumn{4}{|c|}{ Kisaran } \\
\hline & & \multicolumn{2}{|c|}{$\mathrm{FL}(\mathrm{cm})$} & \multicolumn{2}{|c|}{ W (gr) } \\
\hline & & Min & $\operatorname{Max}$ & Min & $\operatorname{Max}$ \\
\hline 1 & Kurisi bali & 15.0 & 21.5 & 40 & 160 \\
\hline 2 & Kakap merah & 18.5 & 29.0 & 80 & 300 \\
\hline 3 & Lencam/ Tambak & 22.0 & 51.5 & 190 & 1.890 \\
\hline 4 & Kakap sawo & 21.0 & 28.5 & 205 & 420 \\
\hline 5 & Lemcam/ Jenaha & 19.0 & 25.5 & 100 & 190 \\
\hline 6 & Tanda-tanda & 20.0 & 29.5 & 140 & 360 \\
\hline 7 & Kuwe/ Gerong & 19.0 & 39.5 & 150 & 940 \\
\hline 8 & Kitang/ Kiper & 22.0 & 45.5 & 130 & 940 \\
\hline 9 & Daun bambu/ Kelempes & 25.0 & 33.5 & 90 & 340 \\
\hline 10 & Tenggiri batang & 20.0 & 45.5 & 100 & 620 \\
\hline 11 & Kurisi & 17.4 & 22.5 & 11 & 21 \\
\hline 12 & Tenggiri & 57.5 & 90.5 & 580 & 7.500 \\
\hline 13 & Kerapu merah & 21.6 & 24.0 & 110 & 210 \\
\hline 14 & Kerapu sunu/ Lodi & 21.0 & 33.5 & 110 & 570 \\
\hline 15 & Kakap merah/ Ganas & 18.4 & 64.5 & 75 & 3.280 \\
\hline 16 & Kerapu lumpur & 22.0 & 45.5 & 130 & 940 \\
\hline
\end{tabular}

